\title{
Ghost Images in DECam
}

with thanks to the Eyeball Squad

DARK ENERGY SURVEY

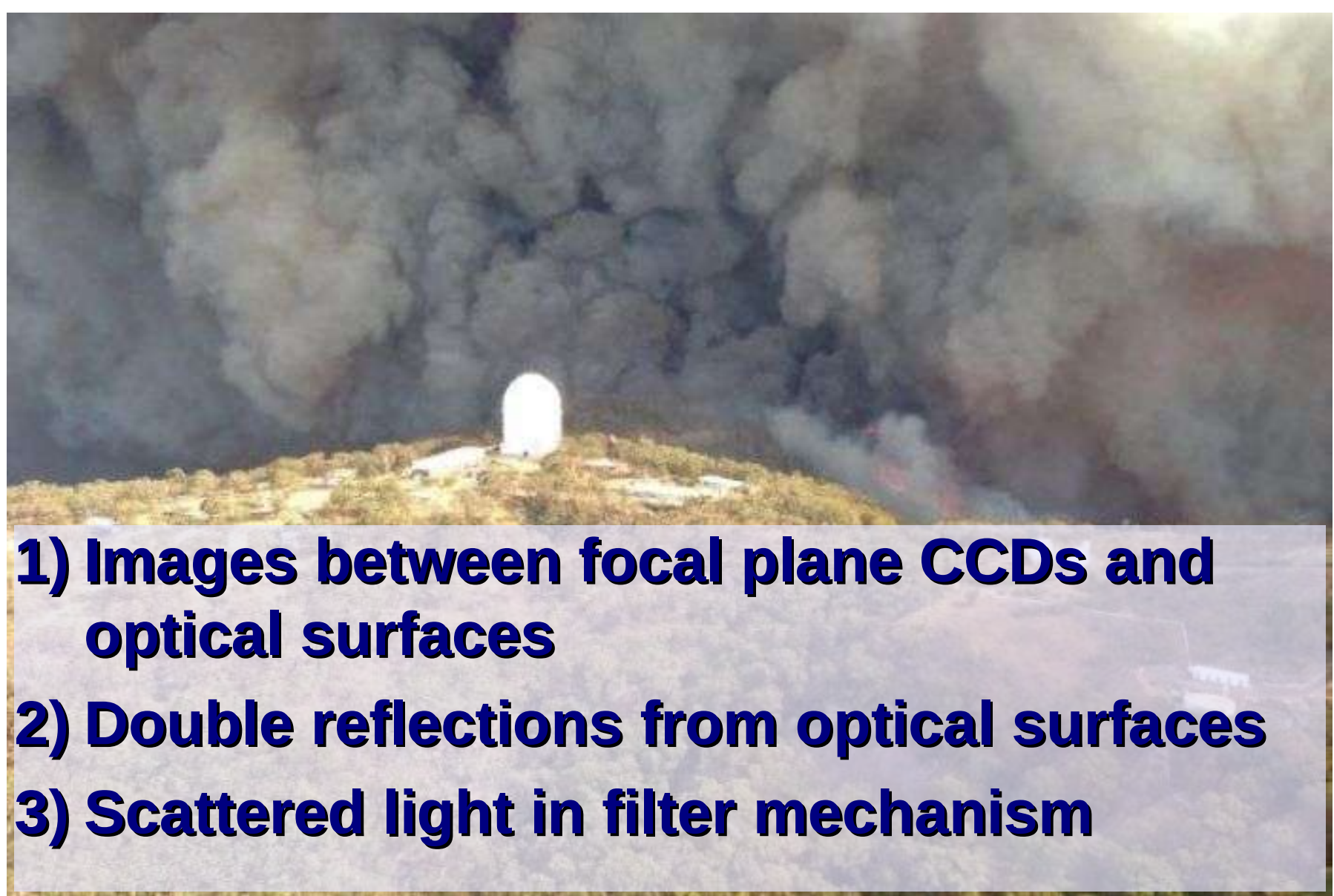

S. Kent, Jan 16, 2013

This manuscript has been authored by Fermi Research Alliance, LLC under Contract No. DE-AC02-07CH11359 with the U.S. Department of Energy, Office of Science, Office of High Energy Physics. 


\section{CCD + Filter}

DARK ENERGY SURVEY

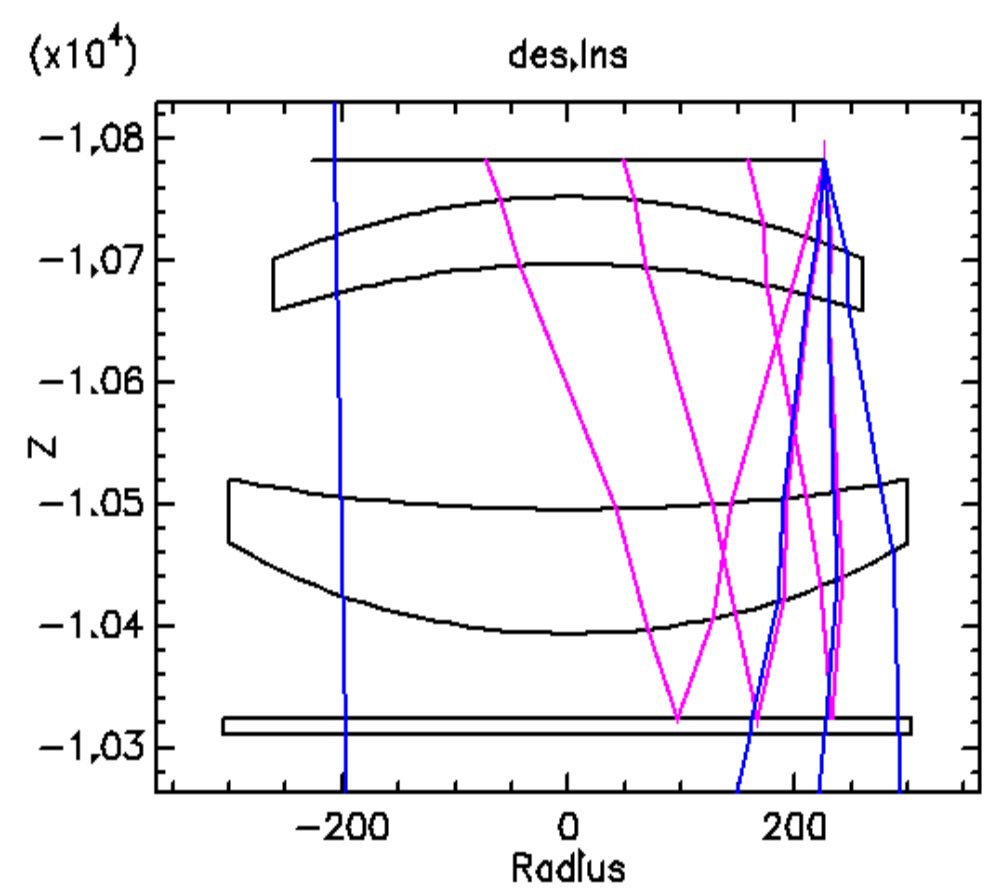

S. Kent, Jan 16, 2013

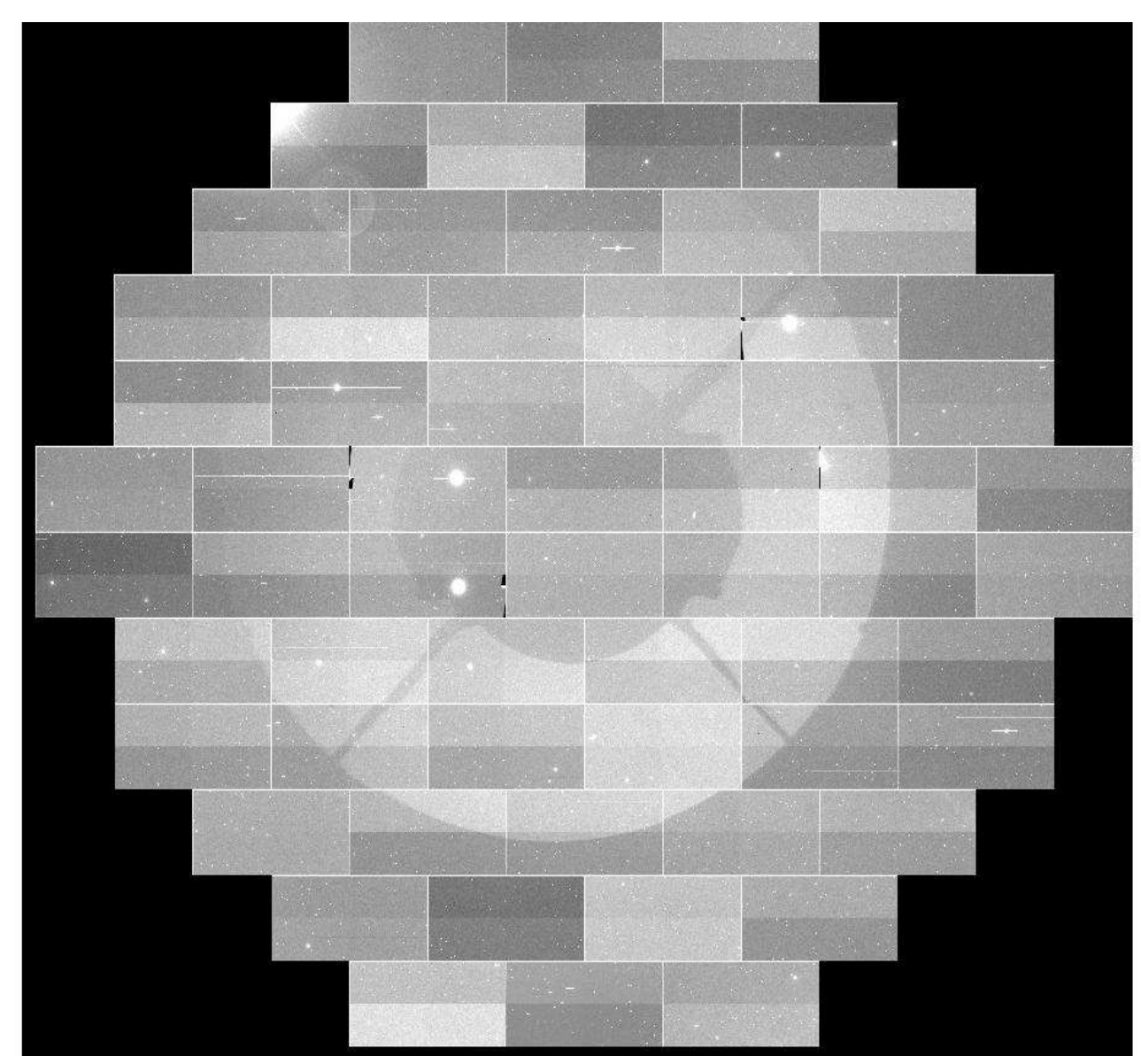

Exit pupil ghost of $\mathbf{R}$ Doradus 157555 


\section{CCD + Rear C5}

\section{DARK ENERGY}

SURVEY
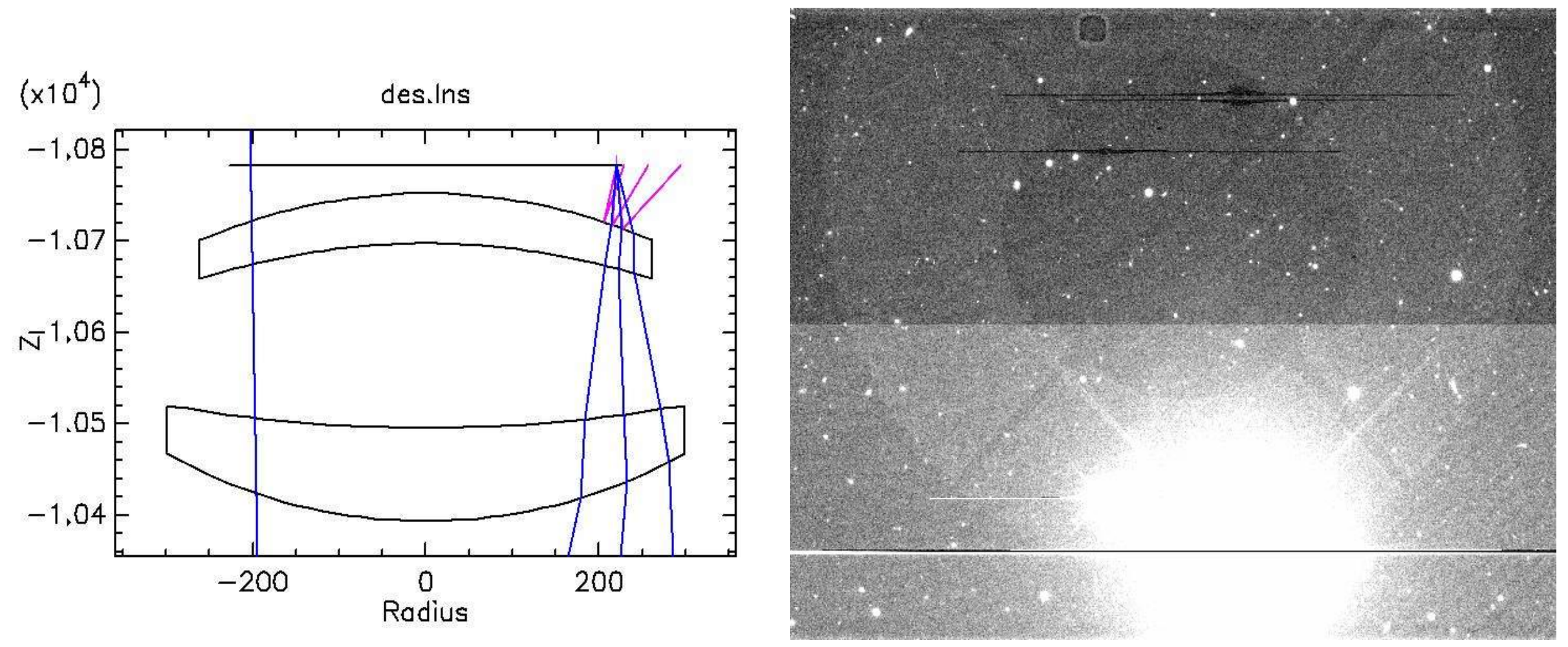

Ghost of Mira 150983

S. Kent, Jan 16, 2013 


\section{$\mathrm{CCD}+$ Front $\mathrm{C} 5$}

DARK ENERGY SURVEY

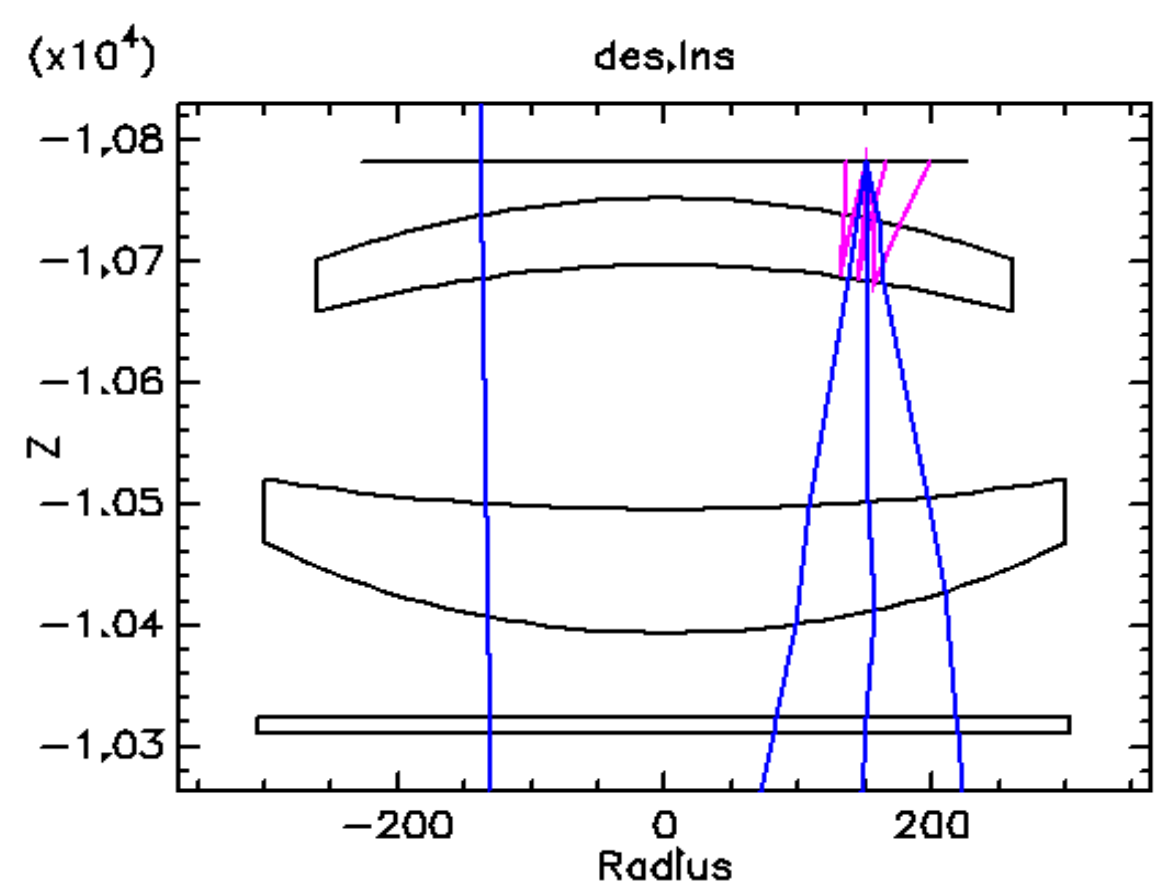

S. Kent, Jan 16, 2013 


\section{CCD + Front $\mathrm{C} 4$}

DARK ENERGY

DAMU.,

$\left(\times 10^{4}\right)$

des,lns

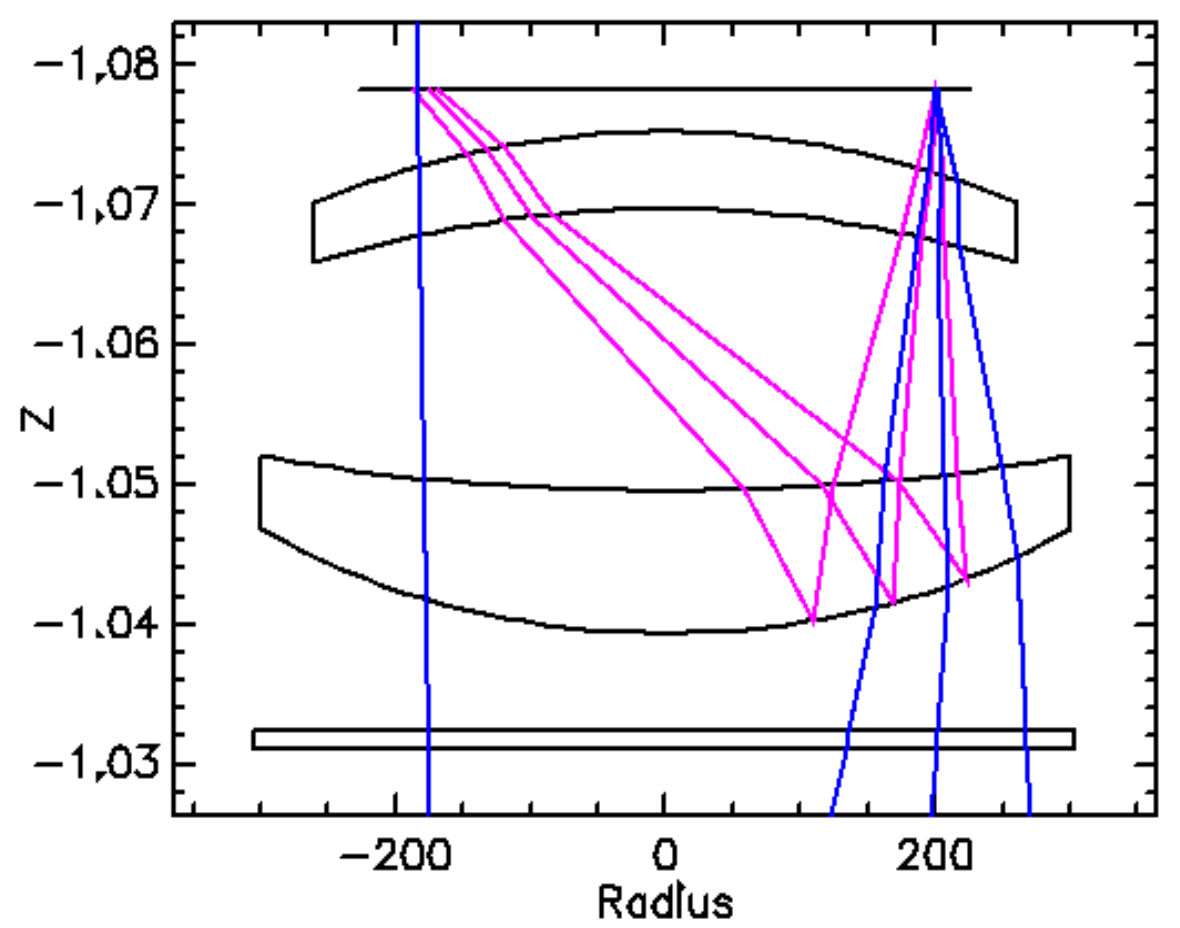

S. Kent, Jan 16, 2013

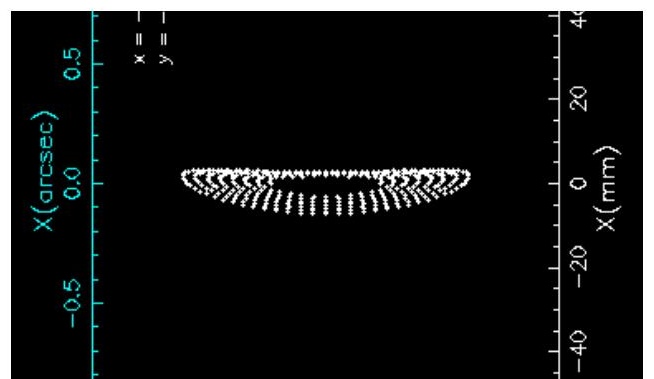

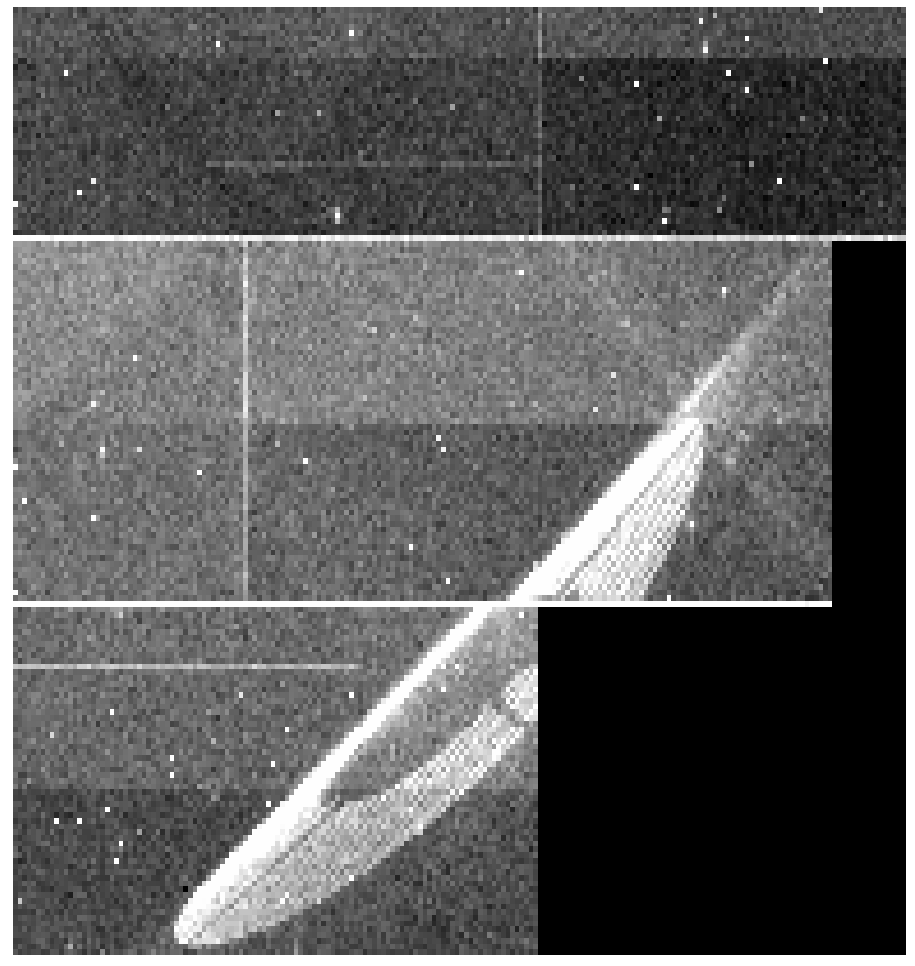

Ghost of R Doradus 157556 


\section{Double Internal Reflection - Filter}

DARK ENERGY

SURVEY

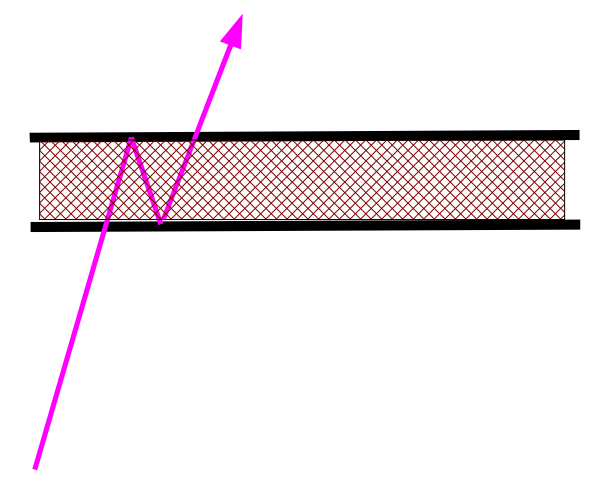

Ray bouncing inside a filter

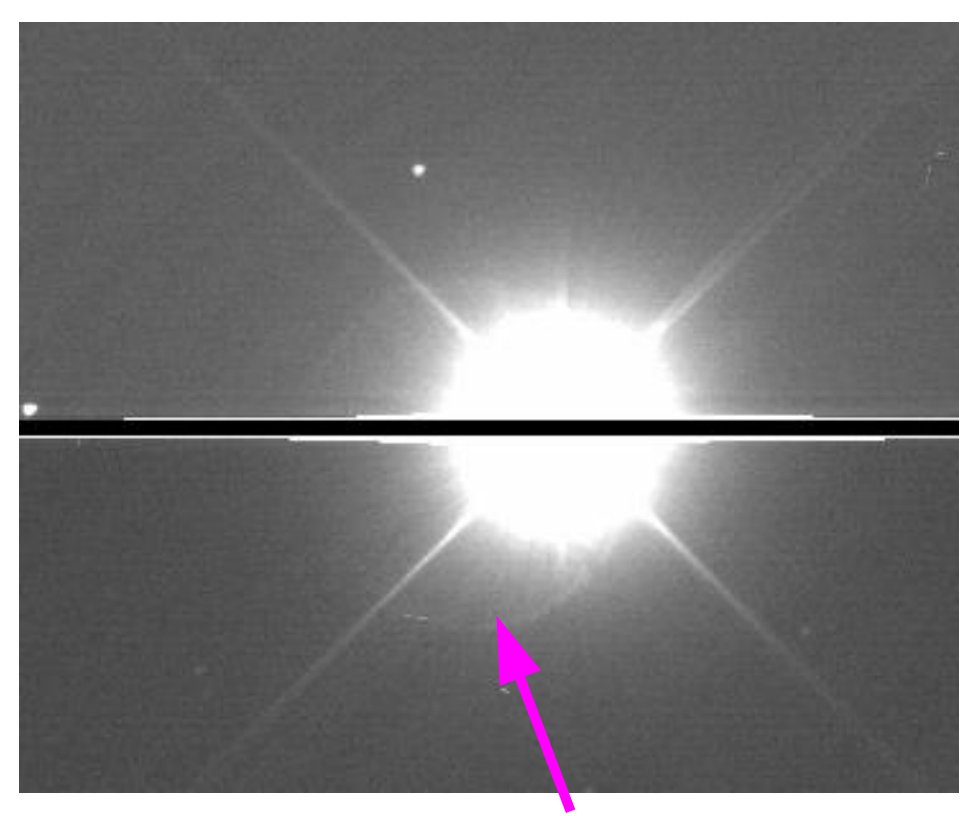

Ghost

Bright star in Orion Region, z filter 150720 


\section{Scattered Light from Filters/Shutter}

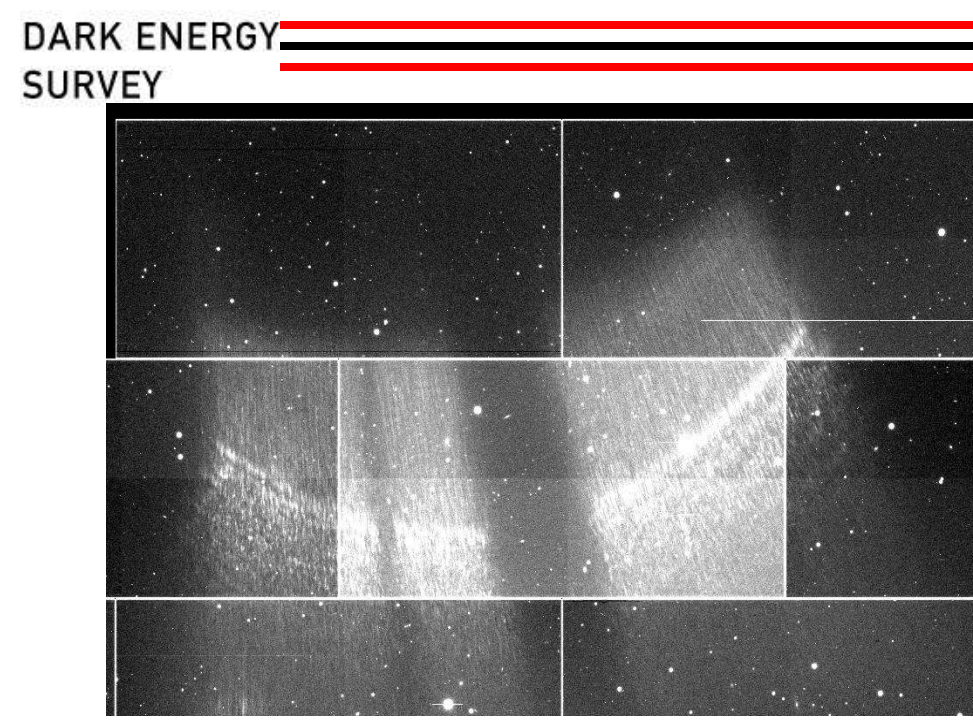

Mira g-band 149251

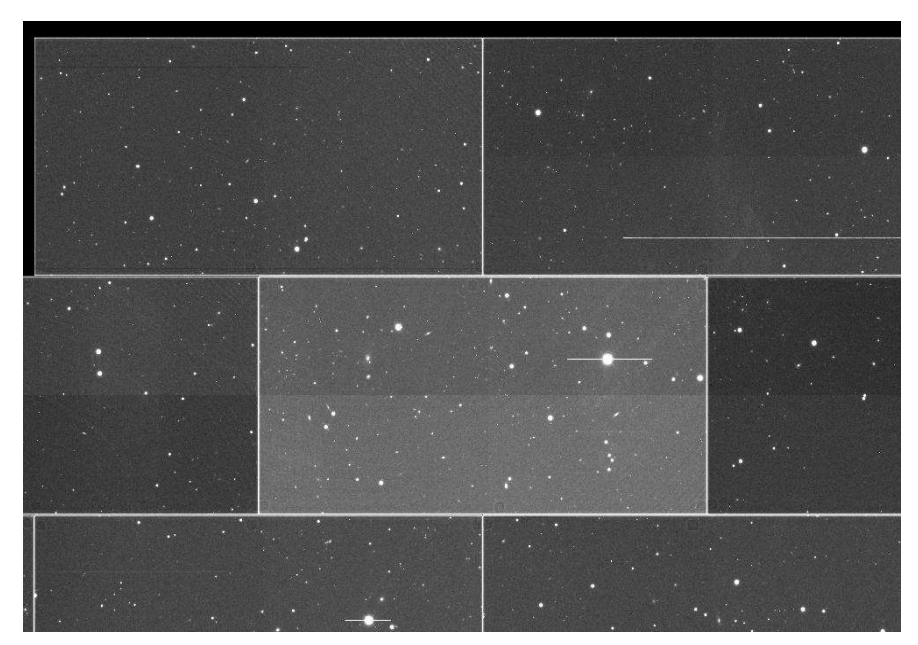

S. Kent, Jan 16, 2013 Mira r-band 149252

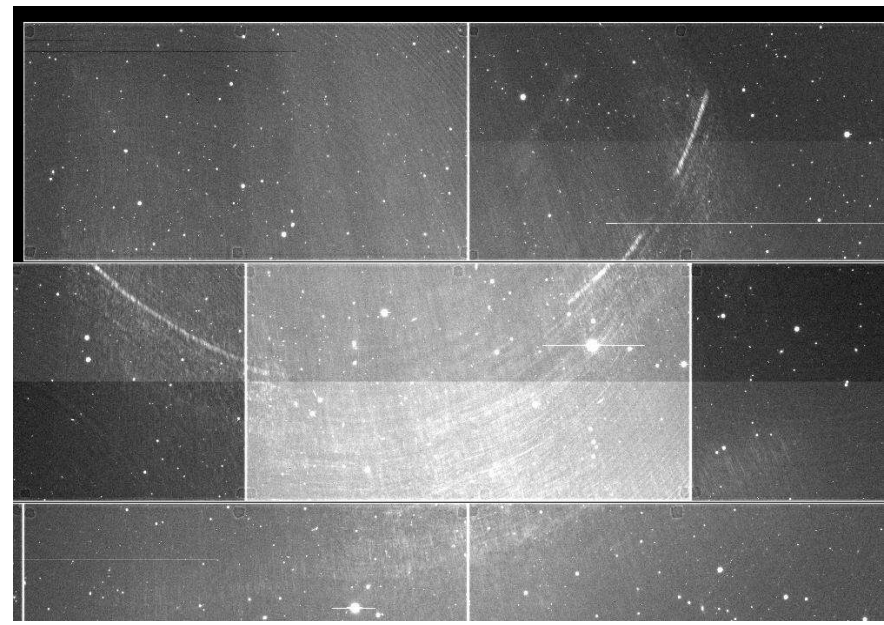

Mira 1.67 Degrees off-axis

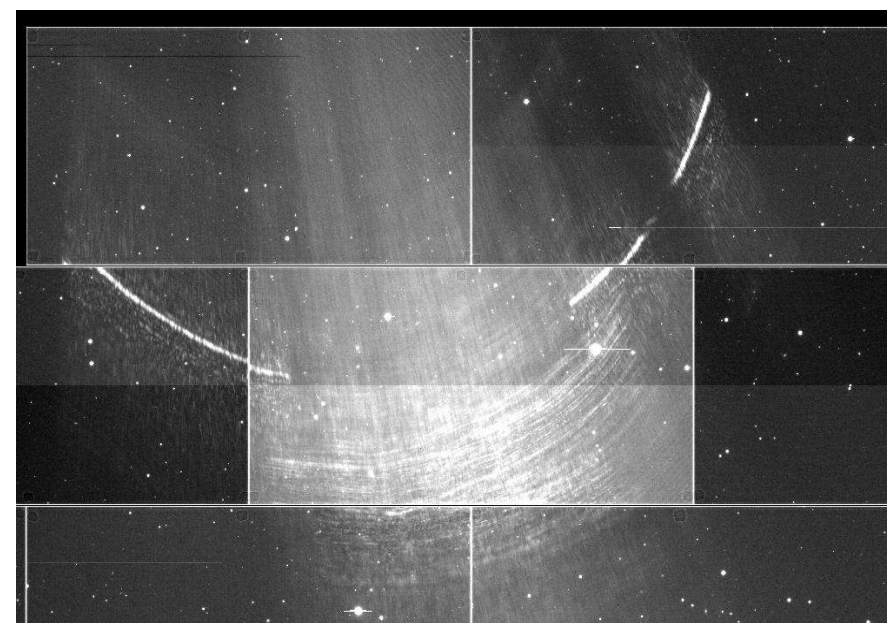

Mira z-band 149251 


\section{Scattered Light from Filters/Shutter}

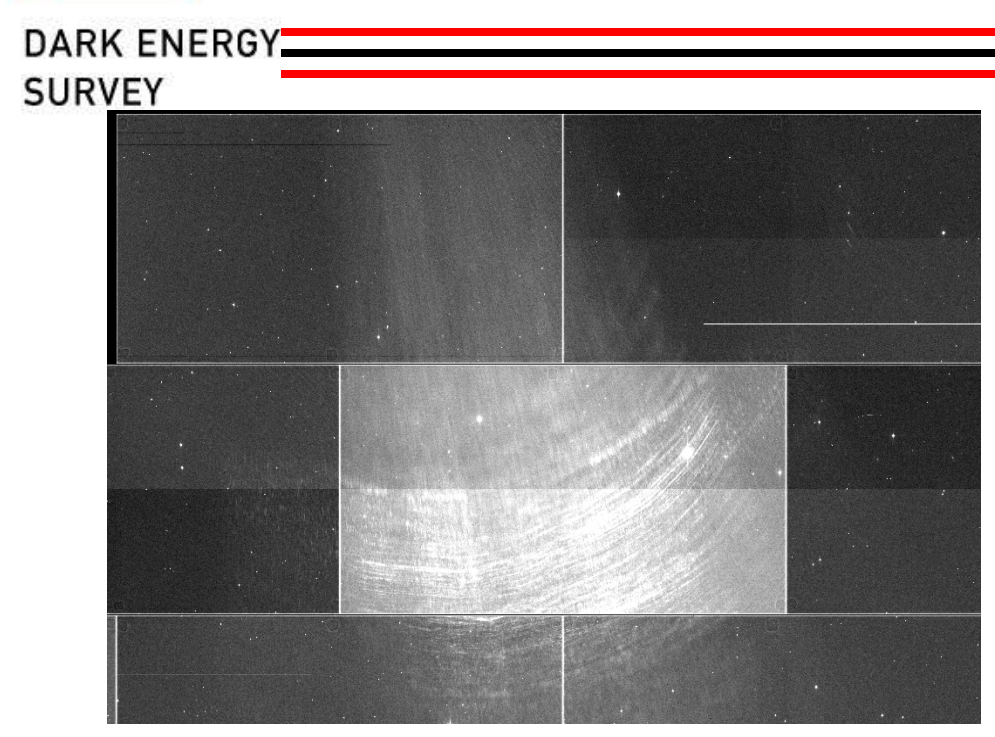

Mira Y-band 149713

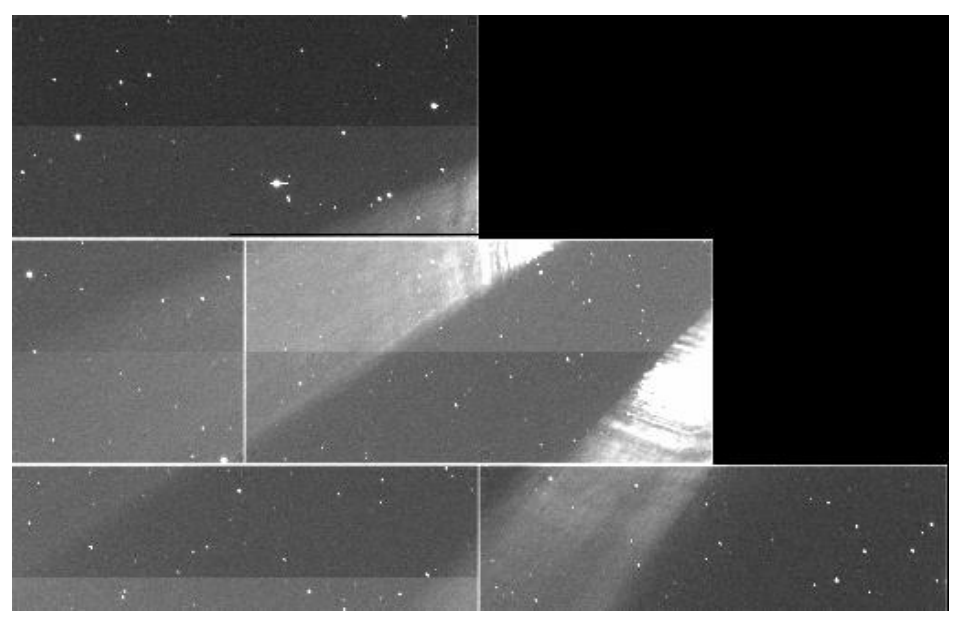

S. Kent, Jan 16, 2013 Mira z-band 153975

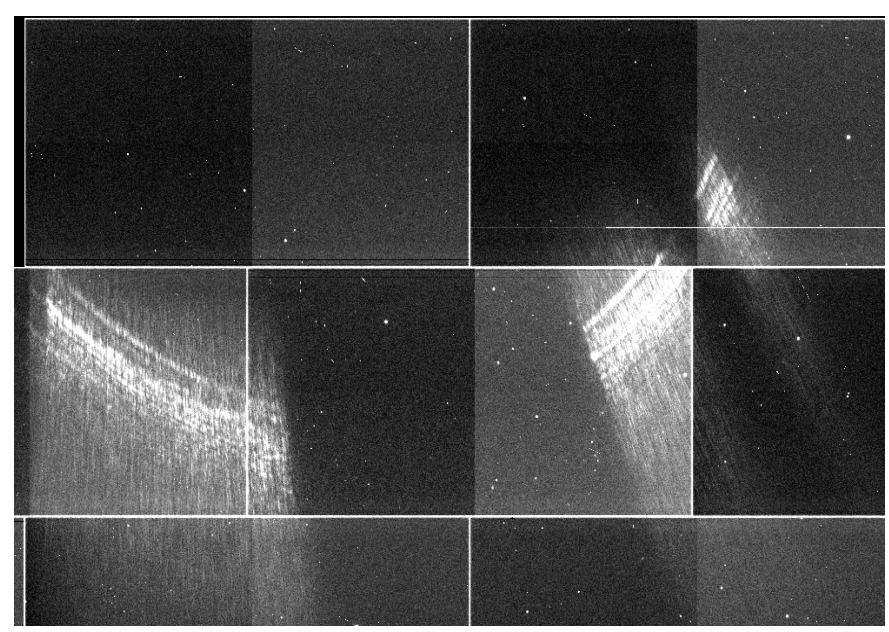

Mira 1.67 Degrees off-axis

Mira u-band 149710

Mira 1.45 Deg. offaxis

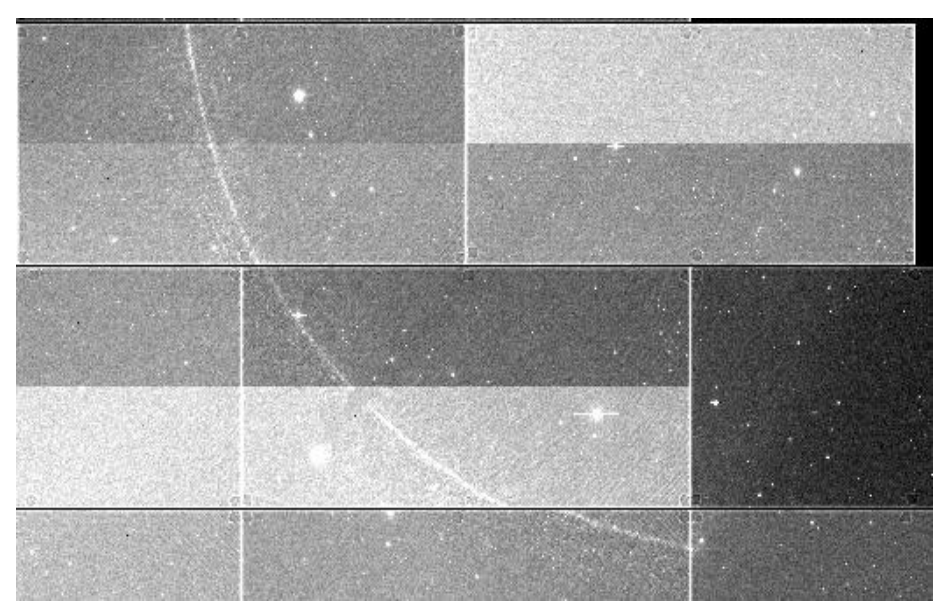

Mira 1.79 Degrees off-axis 


\section{Puzzles - partially solved}

DARK ENERGY SURVEY

- Three types of scattered light:

- Spray (Type I) Y filter is prototype

- Spray (Type II) $g$ filter is prototype

- Arc $\quad z$ filter is prototype

- Raytrace of light reflected from side of filter has correct location, shape in focal plane BUT specular reflected rays should be blocked by filter frame rim. Rays pass in through uncoated portion of filter

- Unclear what blocks portions of arc Fins and Central "chimney"

- Origin of "spray" (Type I) is unclear Inside shutter wall

- Origin of "arc" still unclear 


\section{Central "chimney"}

\section{DARK ENERGY}

SURVEY

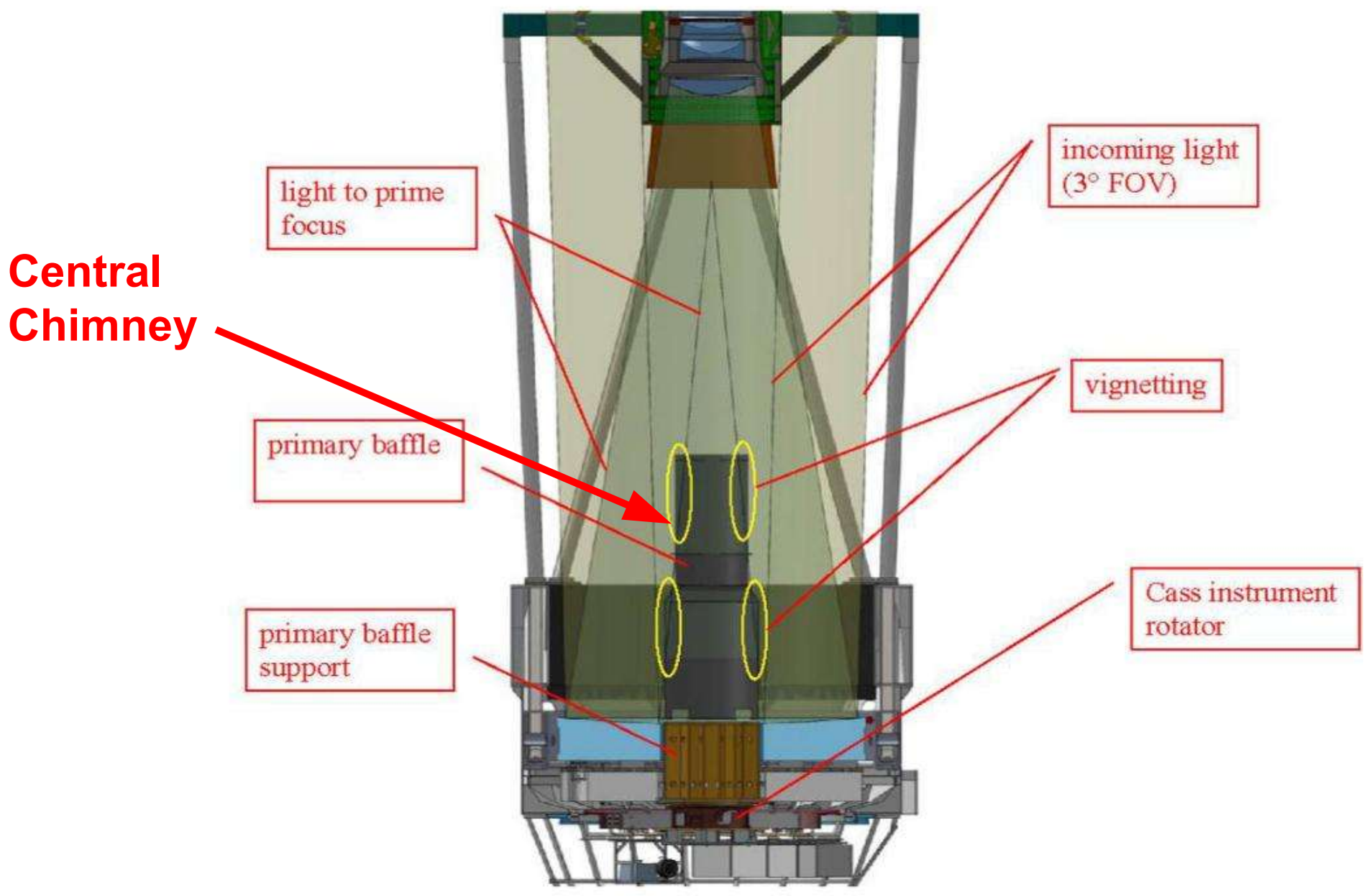

Figure 11: Vignetting of reflected light by the current Mayall primary baffle for the BigBOSS $3^{\circ} \mathrm{FOV}$.

S. Kent, Jan 16, 2013 


\section{Geometry at Filter}

DARK ENERGY SURVEY

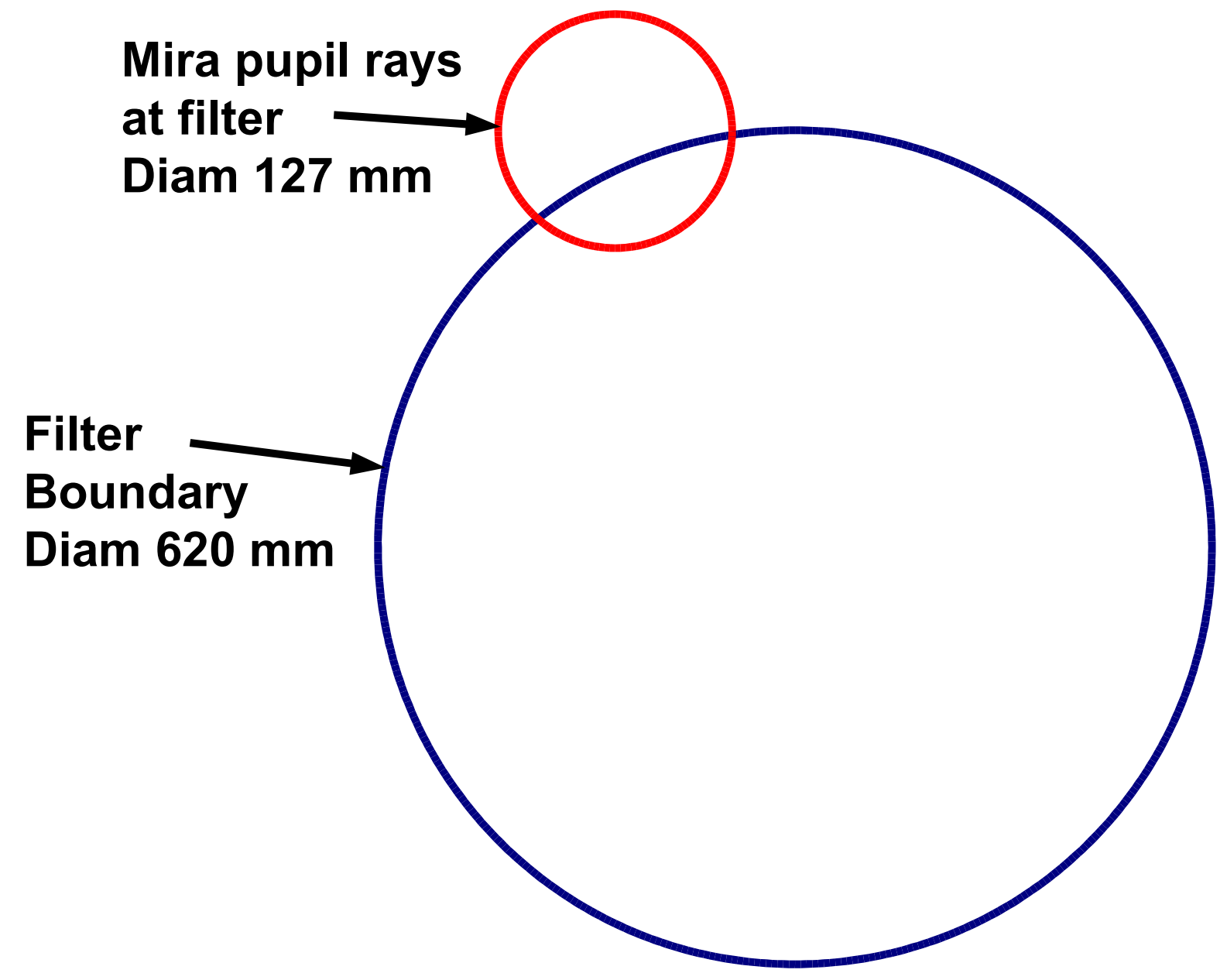




\section{Rays from beam that strike filter}

\section{edge}

DARK ENERGY

SURVEY

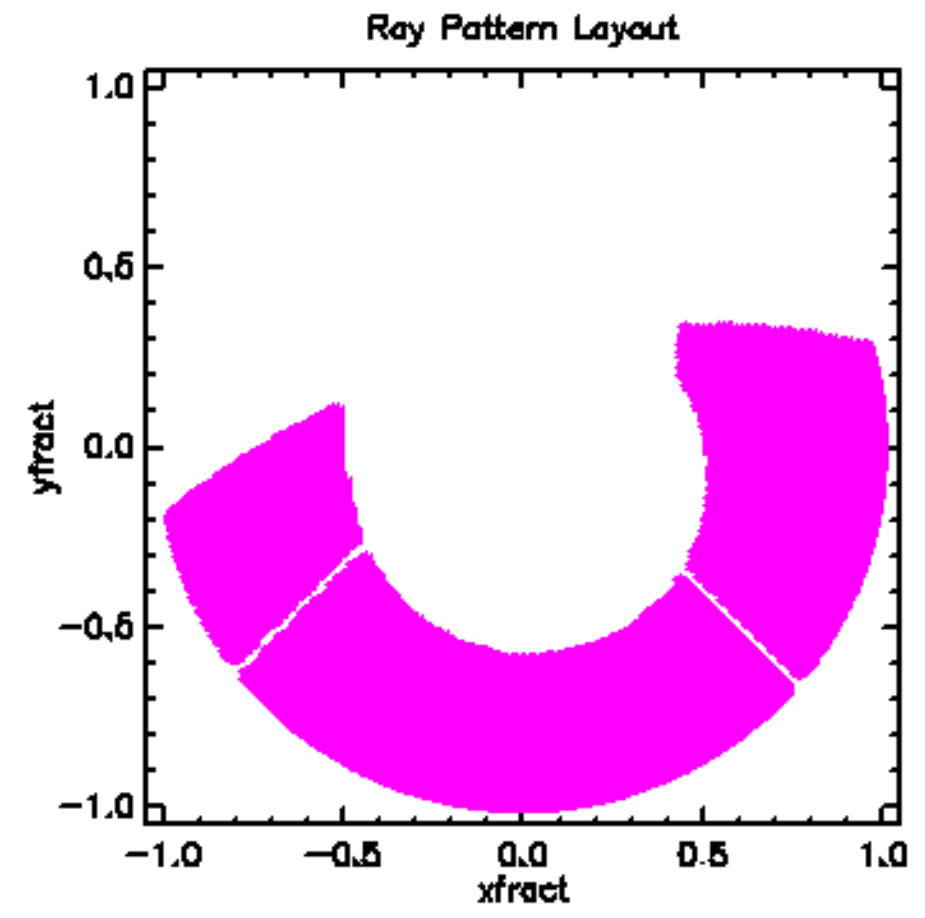

Full pupil, 1.67 deg. off-axis

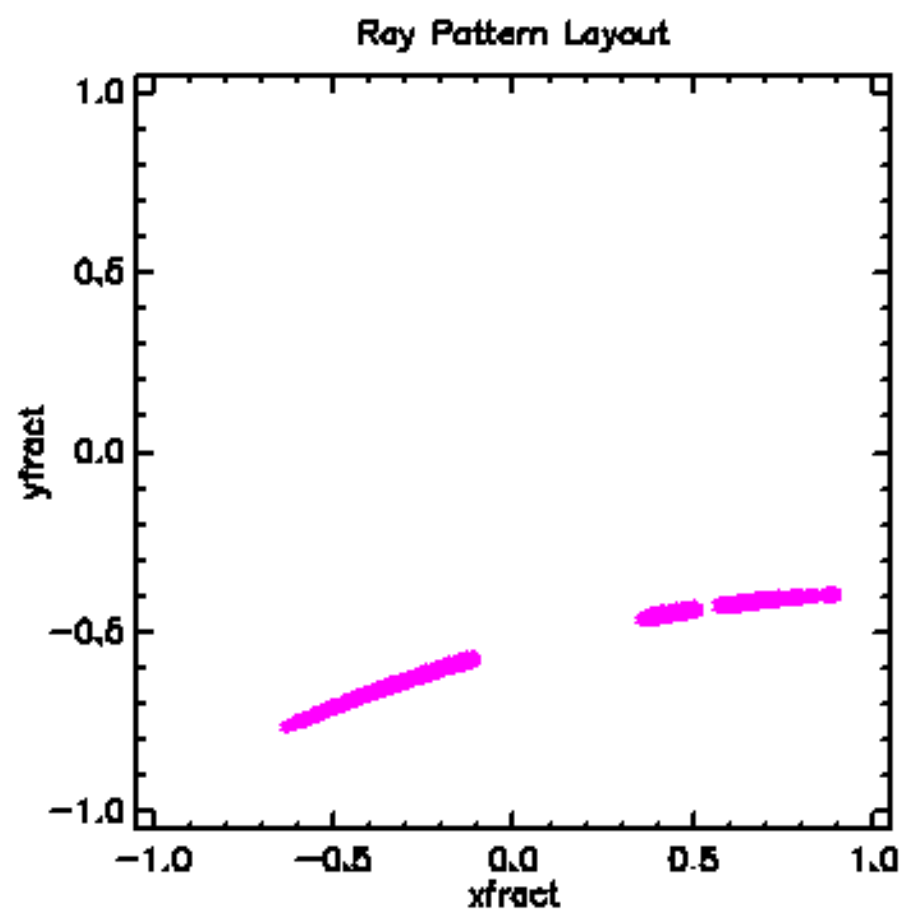

Intersection with edge of $\mathbf{g}$ filter 


\section{Raytrace of Mira - 1.67 degrees from field center, light reflected from filter \\ side}

DARK ENERGY SURVEY

$\left(\times 10^{4}\right)$

filterghost, Ins
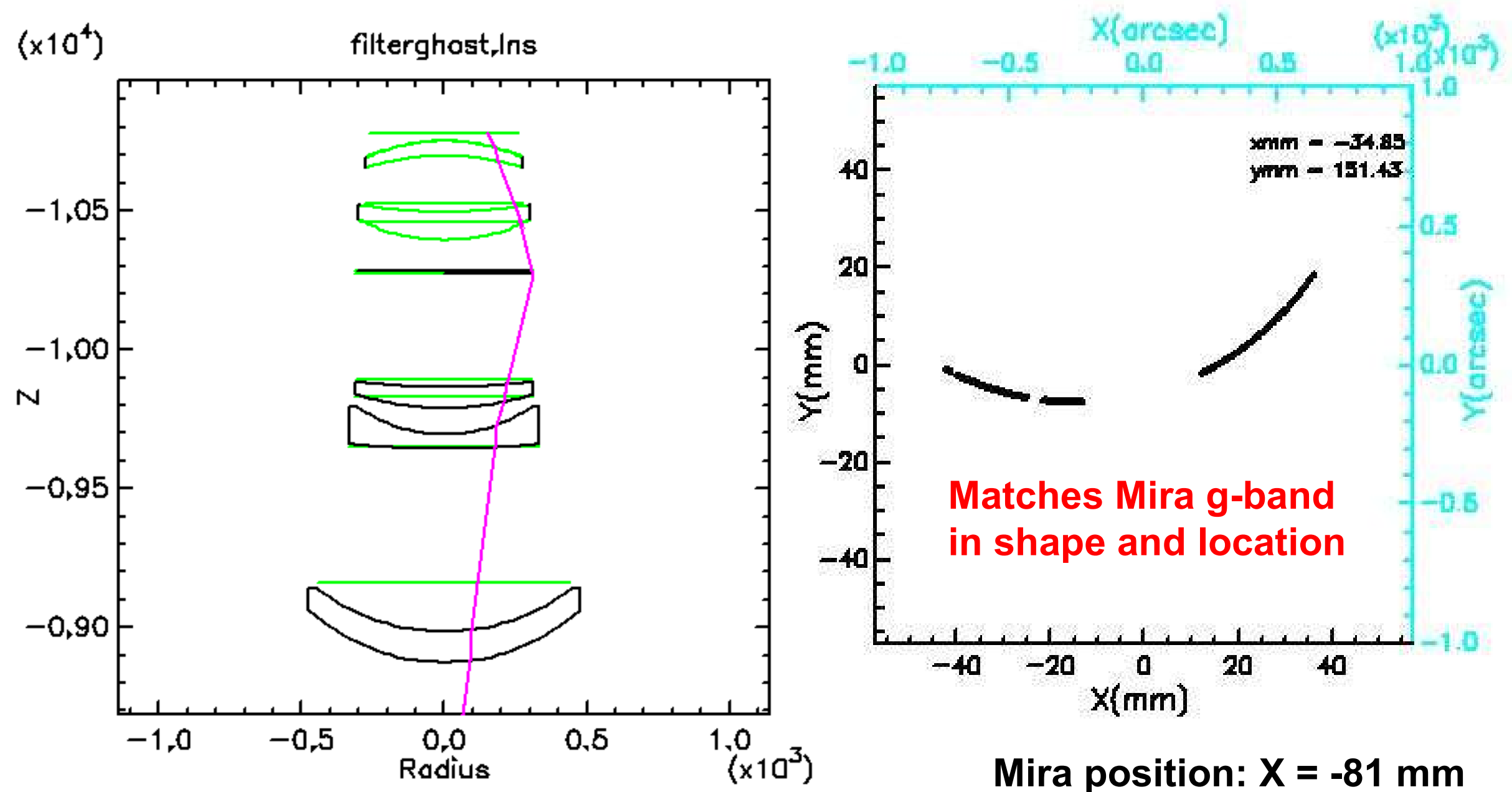

S. Kent, Jan 16, 2013

Mira position: $X=-81 \mathrm{~mm}$

$\mathrm{Y}=334 \mathrm{~mm}$ 


\section{Filter Changer Mechanism}

DARK ENERGY SURVEY

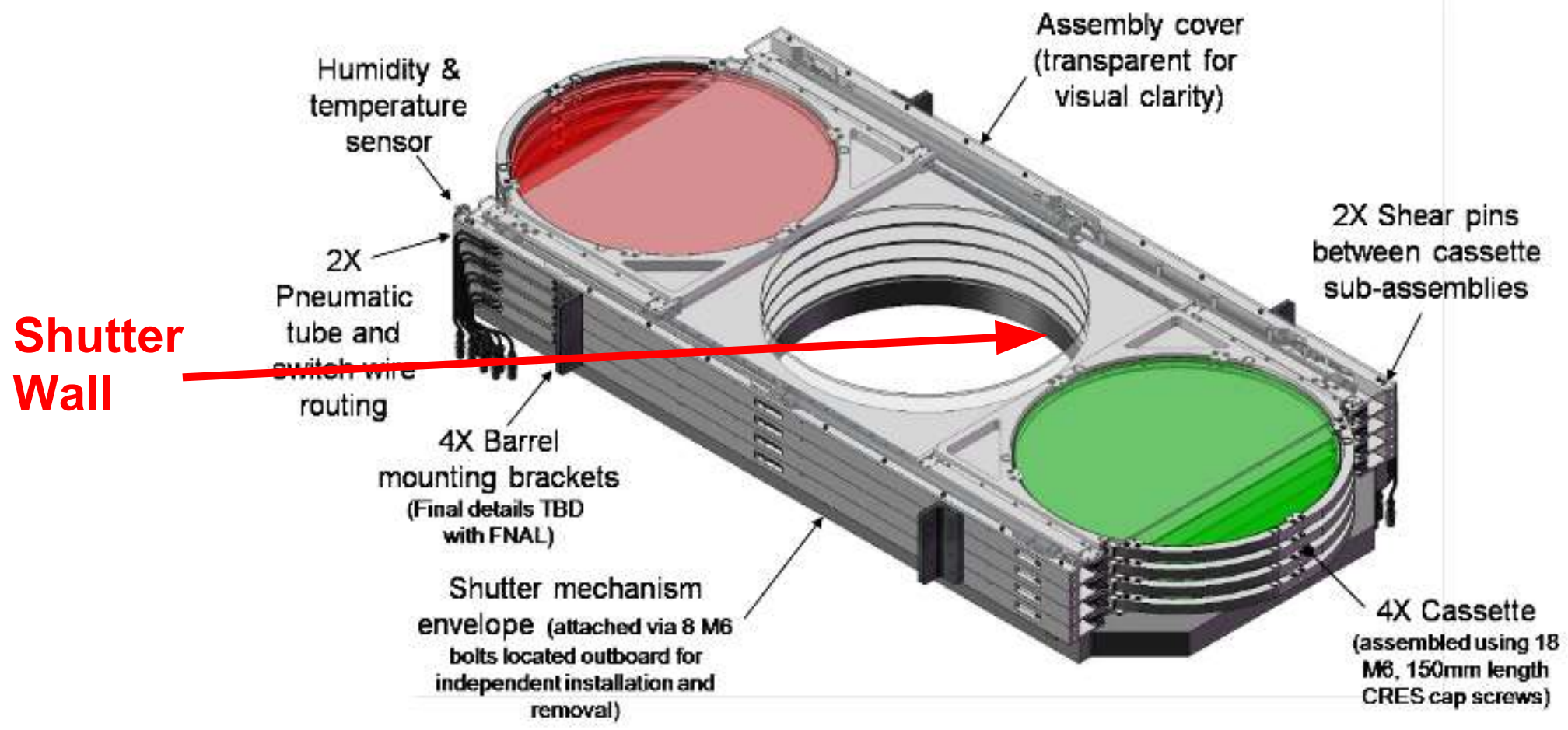

Figure 1: Filter changer mechanism and shutter attached. 


\section{Shop drawings - filter frame}

\section{DARK ENERGY}

SURVEY
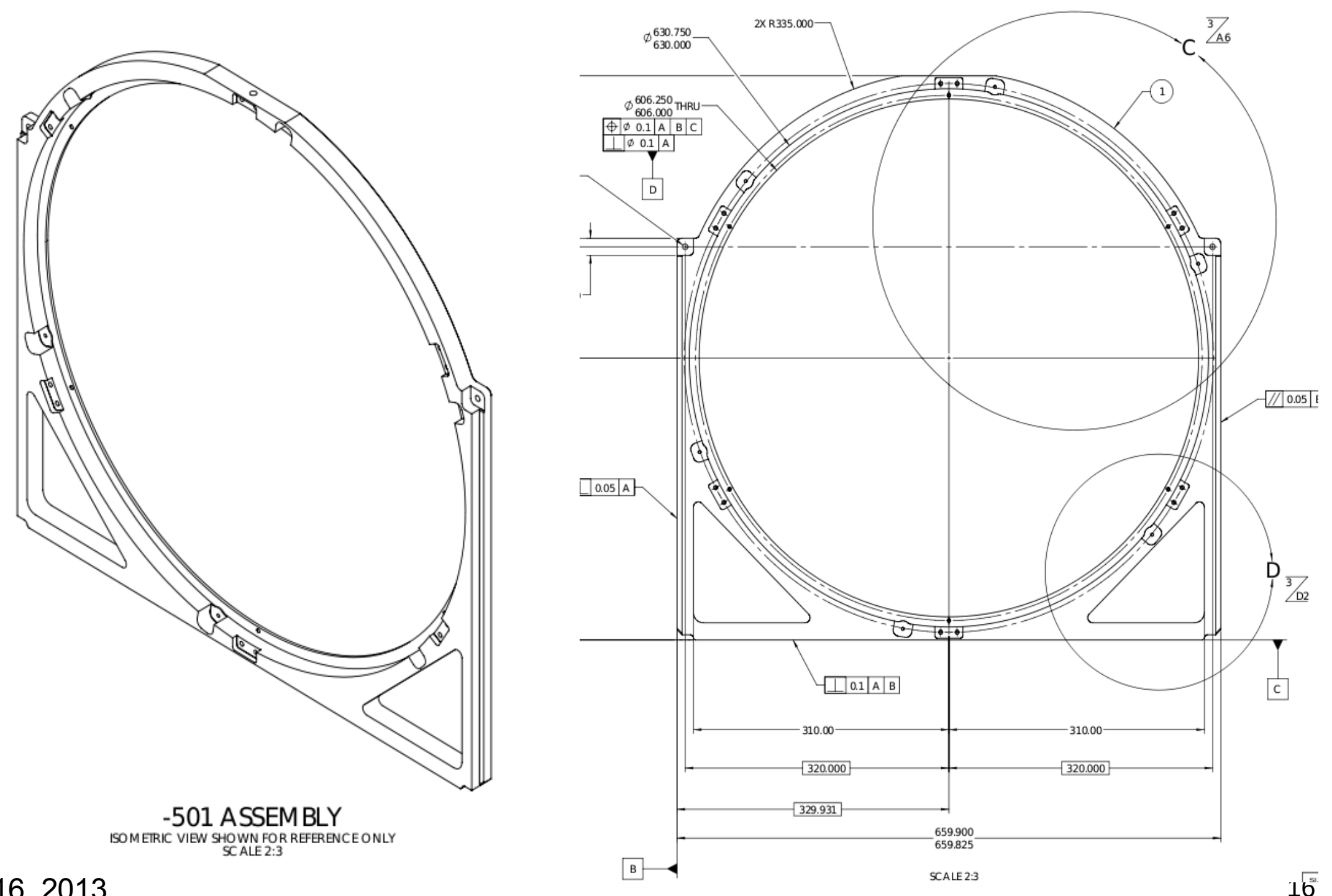

S. Kent, Jan 16, 2013 


\section{Filter Holder Geometry}

\section{DARK ENERGY}

SURVEY

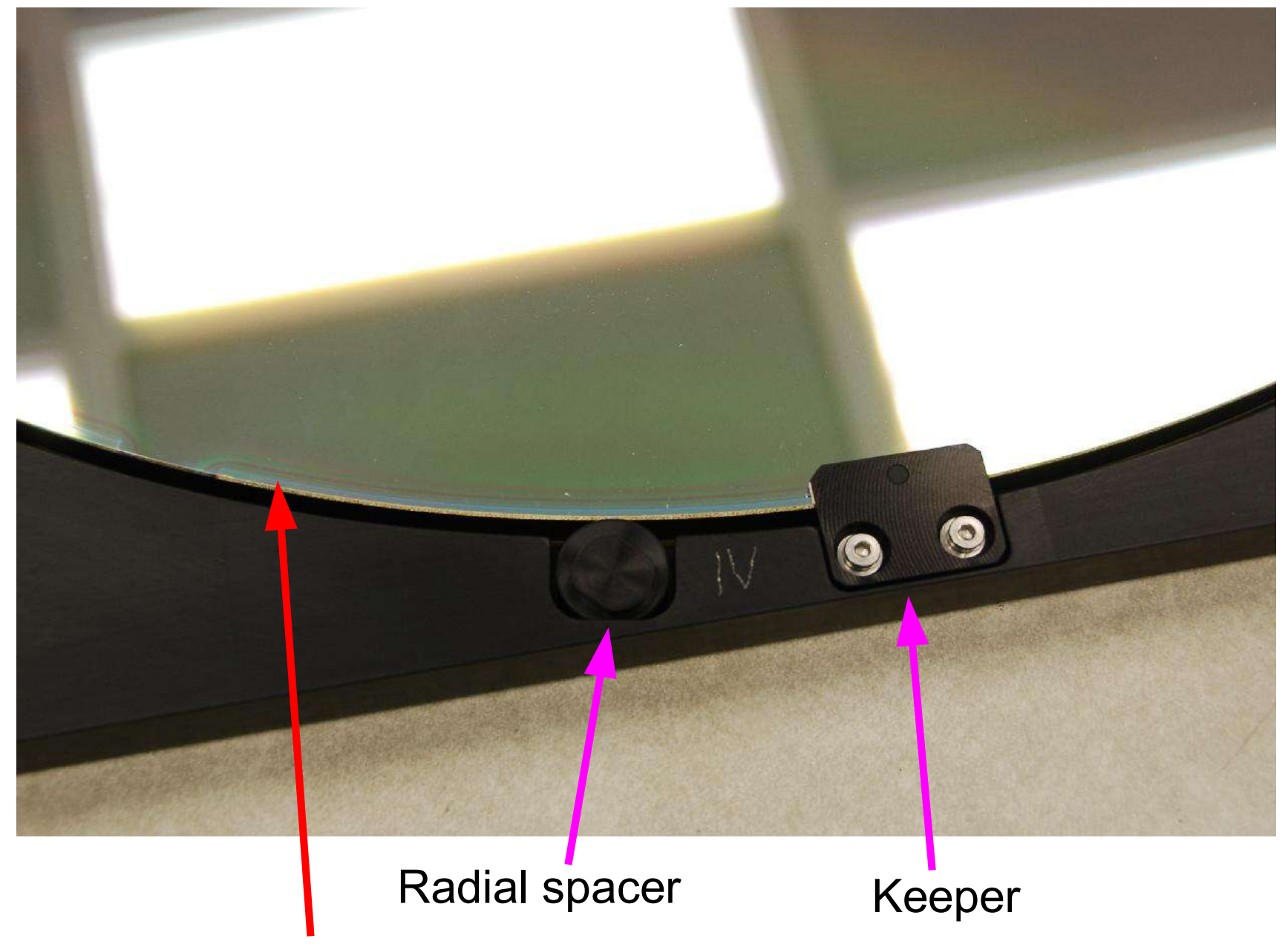

Filter coating does not extend to edge Unwanted light enters here

S. Kent, Jan 16, 2013 


\section{Side View - Spray (Type II)}

DARK ENERGY SURVEY

S. Kent, Jan 16, 2013

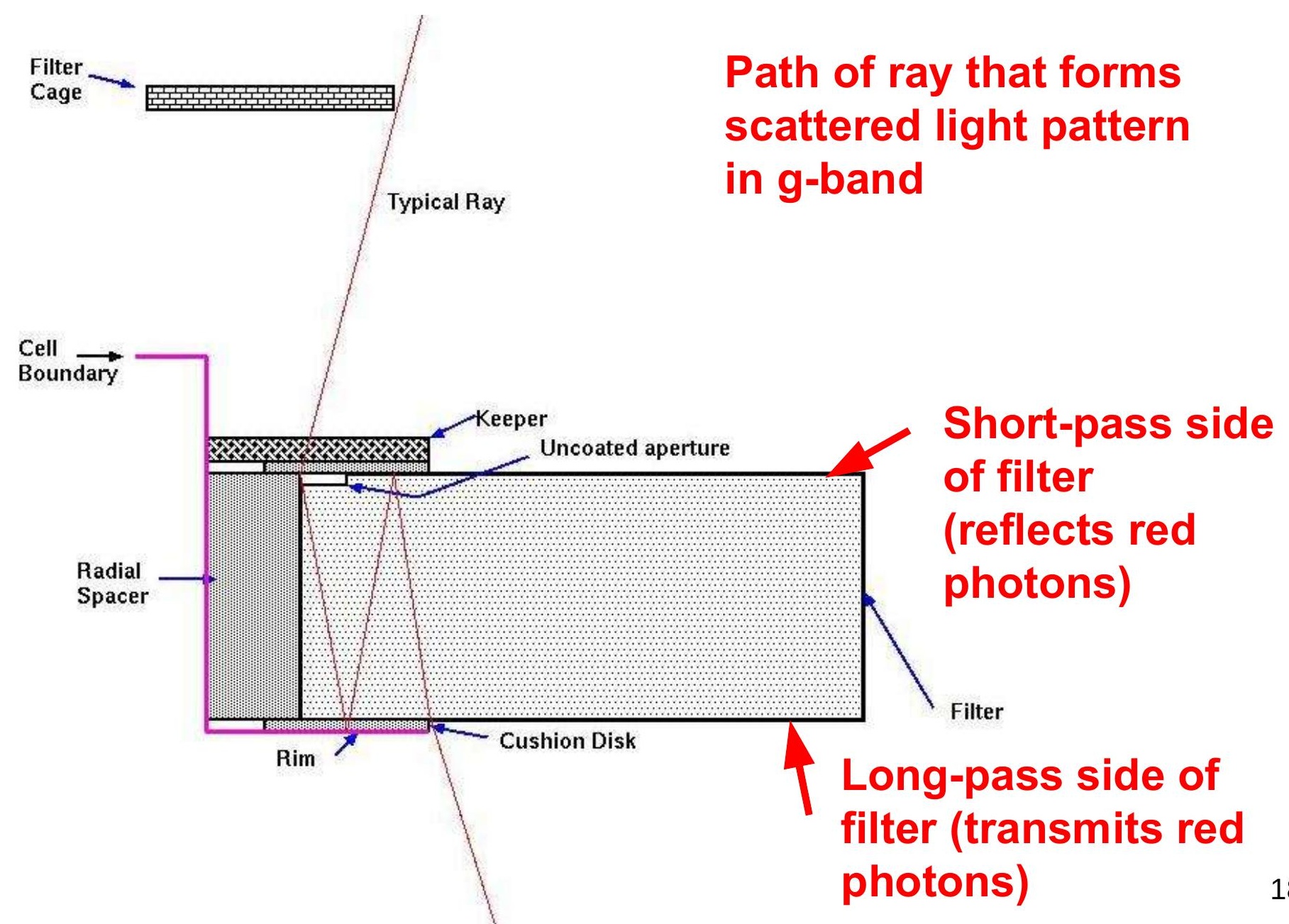




\section{Origin of Arcs - smoking gun}

DARK ENERGY SURVEY

154500

$Z$ band

1.82 deg. off axis
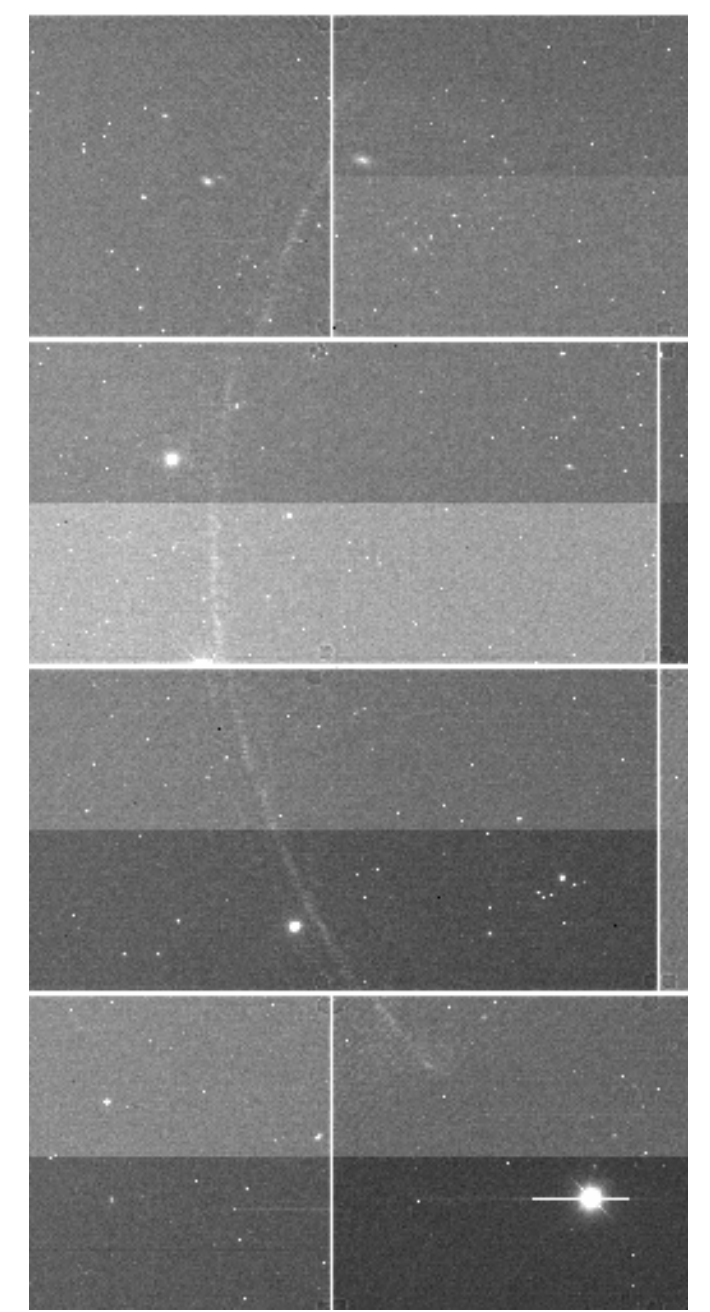

154501

$\mathrm{Y}$ band

1.82 deg. off axis

Faint arc

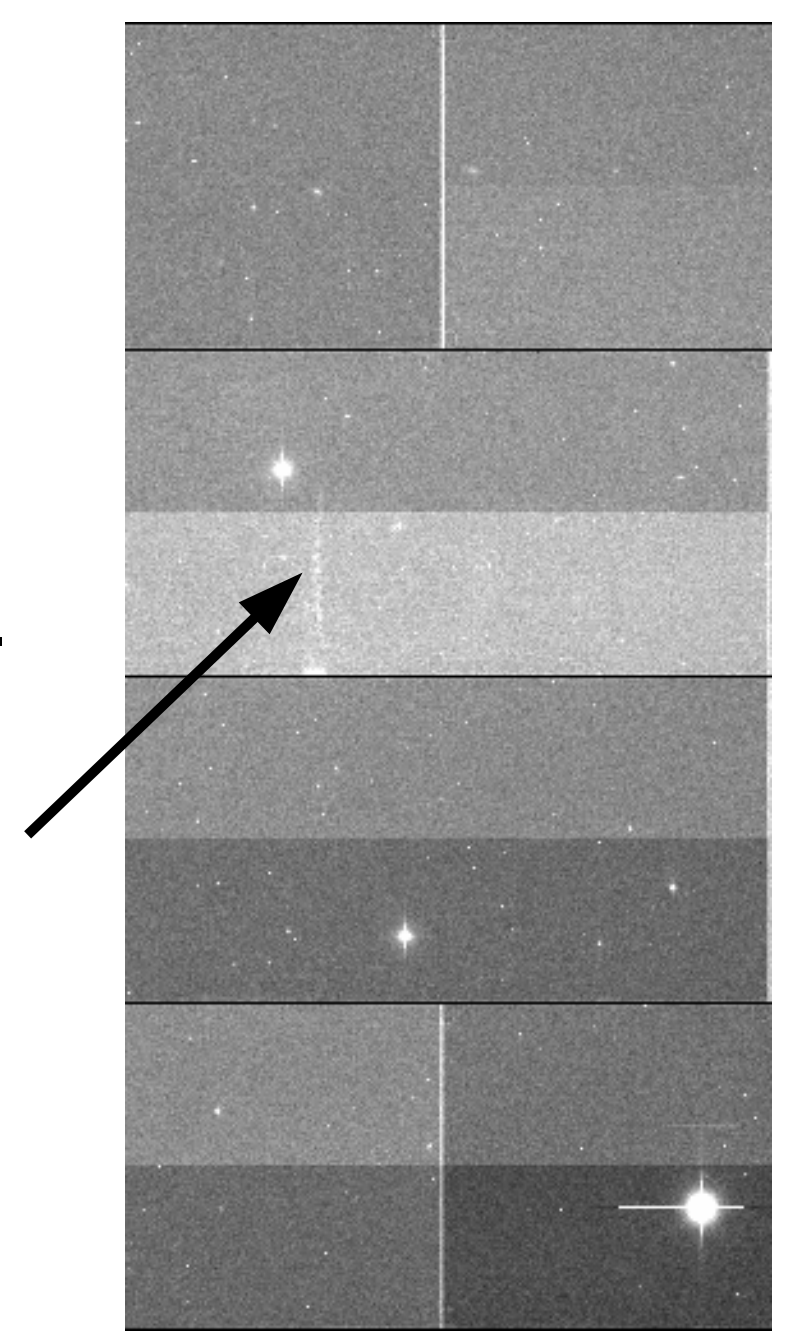

S. Kent, Jan 16, 2013 


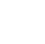

\section{Radius:}

Rim 303 mm

Filter $\mathbf{3 1 0 ~} \mathbf{m m}$

Cell wall $315 \mathrm{~mm}$

Filter cage: $310 \mathrm{~mm}$ (???)

Shutter: $300 \mathrm{~mm}$

S. Kent, Jan

Side View of Filter Cell, Cage, and related showing arc rays for $Y$ filter

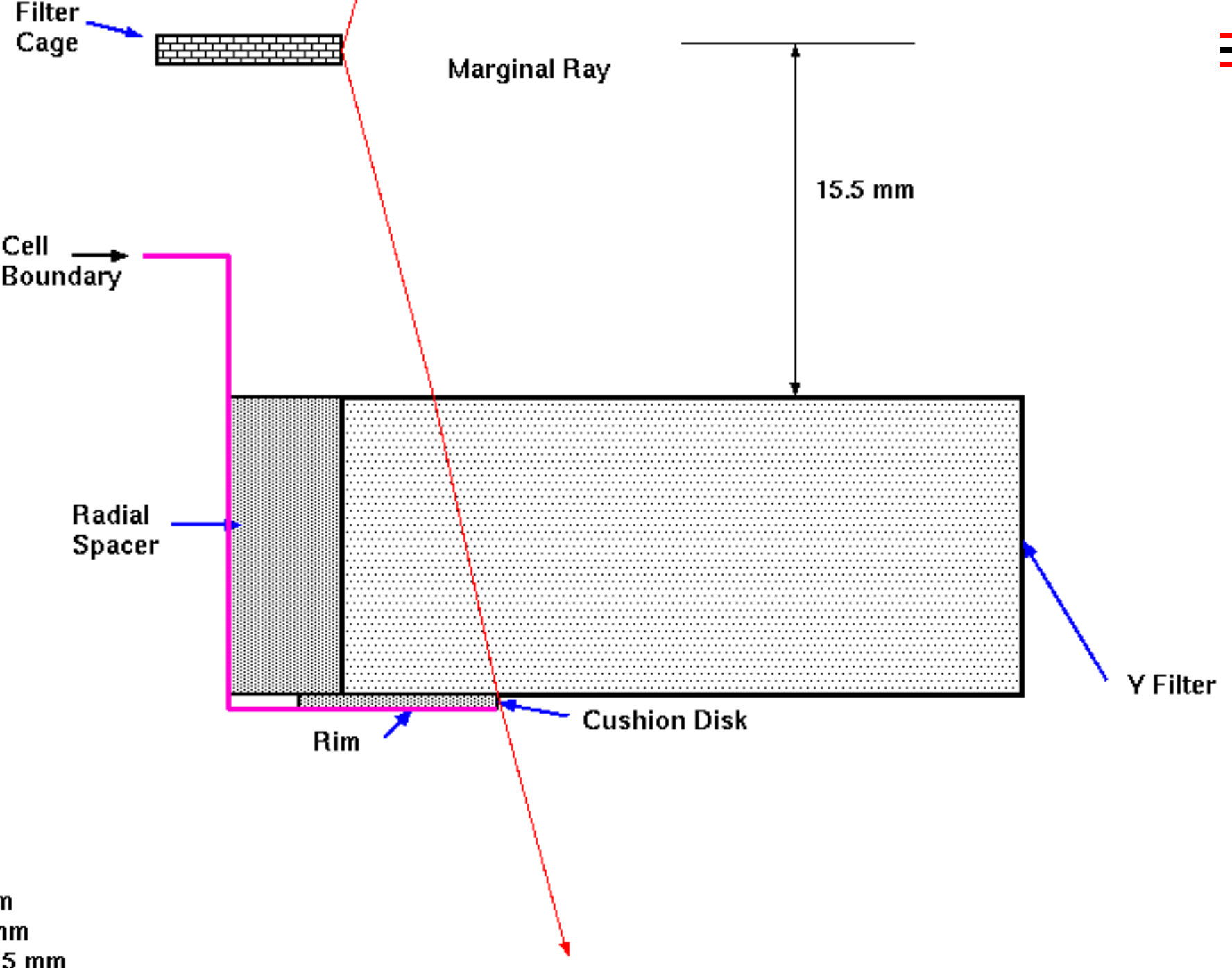




\section{Conclusions}

DARK ENERGY

SURVEY

- Ghost images are all understood. Amplitude is about what is expected for CCDs with 10\%-15\% reflectivity, filters with $1 \%-1.5 \%$ reflectivity.

- Scattered light from bright stars off the field has multiple causes:

- a) Unblocked edges of filters. We definitely want to add baffles to all filters to block light around edges.

- b) Inside shutter wall. We want to either paint the wall with aeroglaze black (or equivalent) or add some baffles

- c) filter cage or some other surface located above u/Y filter cassette. Probably need to examine visually before deciding on a course of action. 